\title{
Role of Interleukin-1 in the Pathogenesis of Experimental Shigellosis
}

Philippe J. Sansonetti, ${ }^{*}$ Josette Arondel, ${ }^{*}$ Jean-Marc Cavaillon, ${ }^{\star}$ and Michel Huerre ${ }^{\S}$

*Unité de Pathogénie Microbienne Moléculaire, Unité 389 Institut National de la Santé et de la Recherche Médicale,

${ }^{\ddagger}$ Unité d'Immuno-Allergie, ${ }^{8}$ Unité d'Histopathologie, Institut Pasteur, F-75724 Paris Cédex 15, France

\begin{abstract}
The effect of human recombinant interleukin-1 receptor antagonist on intestinal inflammation, tissue destruction, and bacterial invasion during experimental shigellosis caused by Shigella flexneri was studied in the rabbit-ligated loop infection model. Intravenous infusion of the inhibitor at a dose of $2 \mathrm{mg} / \mathrm{kg}$ per $\mathrm{h}$, was initiated $30 \mathrm{~min}$ before intestinal loops were ligated and infected, and continued during the 8$h$ period of infection. The animals treated with $I L-1$ receptor antagonist showed a striking decrease in inflammation, destruction, and bacterial invasion of their tissues, both at the level of the villous intestine and Peyer's patches. This is conclusive evidence that interleukin-1 plays a critical role in the pathogenesis of shigellosis. This proinflammatory cytokine is here proposed as a major trigger of the inflammatory reaction which is characteristic of this invasive disease of the intestine, due to the particular interaction existing between $S$. flexneri and macrophages. (J. Clin. Invest. 1995. 96:884-892.) Key words: shigellosis • invasion • inflammation • interleukin-1 • interleukin-1 receptor antagonist
\end{abstract}

\section{Introduction}

Shigellosis is an invasive disease of the human colon, caused by Shigella, a gram-negative bacillus of the family enterobacteriaceae. Children in developing areas are the principal victims of this disease which is largely caused, in its endemic form, by Shigella flexneri.

The clinical symptoms of shigellosis range from diarrhea to dysentery, characterized by fever, severe intestinal cramps, and emission of stools containing blood, pus, and mucus.

The disease is caused by penetration of invasive shigellae into the colonic and rectal mucosa. Intestinal cells are generally considered the primary target for the pathogen (1). As recently reviewed, in vitro experiments demonstrate that Shigella has the capacity to establish efficient intracellular colonization of an epithelial layer by hijacking components of the host cell cytoskeleton both for entry and for cell to cell spread (2).

Address correspondence to Philippe J. Sansonetti, Unité de Pathogénie Microbienne Moléculaire, Institut National de la Santé et de la Recherche Médicale U389, Institut Pasteur, 28 rue du Dr. Roux, F-75724 Paris Cédex 15, France. Phone: 33-1-45-68-83-42; FAX: 33-1-45-6889-53; E-mail:psanson@pasteur.fr.

Received for publication 22 February 1995 and accepted in revised form 17 April 1995.

J. Clin. Invest.

(C) The American Society for Clinical Investigation, Inc.

0021-9738/95/08/0884/09 \$2.00

Volume 96, August 1995, 884-892
Mutants unable to enter cells are avirulent in vivo, and those impaired in cell to cell spread express attenuated virulence in a model of dysentery in macaque monkeys (3).

However, several observations indicate that shigellosis is not exclusively characterized by invasion of colonic and rectal epithelial cells. Acute inflammation occurring early after infection (4) by a small bacterial inoculum (5) may not only account for final mucosal destruction, but also, at an early stage, for disruption of the epithelial barrier, thus facilitating bacterial invasion through the basolateral pole of epithelial cells, which appears to be the essential site of entry (6). This has recently been confirmed in vitro, by showing that invasive shigellae inoculated on the apical side of a differentiated monolayer of human colonic T84 cells are unable to invade these cells. On the other hand, they can promote strong transmigration of PMN deposited on the basal side, thus allowing invasion by opening of the paracellular pathway to the bacteria (7). In a model of mucosal invasion in rabbit ligated intestinal loops, pretreatment of animals by infusion of an anti-CD18 monoclonal antibody which blocks immigration of PMN leukocytes into the mucosa, decreases bacterial invasion and prevents tissue destruction (8). Shigellosis therefore resembles an acute inflammatory bowel disease, sharing significant clinical and histopathological similarities with ulcerative colitis.

Based on these data, we have recently started to investigate the pathogenesis of this acute inflammatory process. The macrophage appears to be a key player. In vitro, infected macrophages undergo apoptosis when infected with an invasive isolate of $S$. flexneri (9). IpaB, a $62-\mathrm{kD}$ invasin of this species accounts for induction of programmed cell death (10). The period preceding macrophage apoptosis is characterized by the release of large quantities of IL- $1 \alpha$ precursor and mature IL-1 $\beta$ (11). A scheme emerges in which bacteria invade the intestinal barrier, essentially through $M$ cells of the dome epithelium covering the lymphoid follicles of the mucosa $(8,12)$. They are then rapidly translocated to local macrophages, trigger their apoptosis, thus achieving release of significant quantities of $\mathrm{IL}-1$, and triggering a cascade of proinflammatory cytokines. This early inflammatory response is expected to spread from these areas and to destabilize the epithelium, thus facilitating bacterial invasion.

We therefore hypothesized that if IL-1 played a major role at early stages of shigellosis, antagonizing its biological function should have an effect on the development of the disease. This work demonstrates, in a model of mucosal infection of ligated intestinal loops in rabbits, that intravenous infusion of $\mathrm{IL}-1$ receptor antagonist (IL-1ra) ${ }^{1}$ starting 30 min before infection and continuing for the duration of the experiment, causes considerable attenuation of the disease symptoms, encompassing alterations in volume and composition of fluid exudate, tissue

1. Abbreviations used in this paper: IBD, inflammatory bowel disease; IL-1ra, IL-1 receptor antagonist; L/W, length/width. 
architecture, and bacterial invasion. In as much as this animal model reflects the exact pathogenesis of shigellosis, this work demonstrates that $\mathrm{IL}-1$ is a key player mediating invasion and inflammation of the intestinal mucosa in the course of this disease.

\section{Methods}

Bacterial strains and growth conditions. S. flexneri strain M90T, a serotype 5 invasive isolate (13), was used throughout these experiments. Bacteria were routinely grown in Tryptic Soy broth (TSB; Difco Laboratories Inc., Detroit, MI). For animal infections, a confluent culture was obtained on TSB medium after overnight growth at $37^{\circ} \mathrm{C}$. From these plates, a bacterial suspension was established in saline at a concentration of $10^{10}$ bacteria $/ \mathrm{ml}$.

Rabbit intestinal loop assay. A total of 12 New Zealand White rabbits, weighing 2.5-3.0 kg (Charles River Laboratories, St. Aubin les Elbert, France), was used in these studies. Animals were fasted 24 $\mathrm{h}$ before infection and all manipulations were performed under general anaesthesia obtained by intravenous injection of $6 \%$ sodium pentobarbital $(0.5 \mathrm{ml} / \mathrm{kg})$.

Perfusion of IL-1ra was initiated 30 min before intestinal loop ligation. Briefly, local surgery allowed for exposure of the femoral vein. A catheter was inserted, and IL-1ra (Synergen, Boulder, $\mathrm{CO}$ ) diluted in hospital-grade saline was perfused at constant flow, with an electric pump, at a concentration of $2 \mathrm{mg} / \mathrm{kg}$ per h, for a total of $8 \mathrm{~h}$ and 30 min. Control animals were perfused under similar conditions with saline.

Intestinal segments of $10 \mathrm{~cm}$ in length were ligated, some of which contained a Peyer's patch. The blood supply was carefully preserved while ligation was performed. In each loop, $0.5 \mathrm{ml}$ of a bacterial suspension containing $10^{10}$ bacteria/ml was injected. The abdominal cavity was then closed and animals were killed $8 \mathrm{~h}$ later. Ligated intestinal loops were dissected. The volume of fluid exudate was aspirated and measured. $1 \mathrm{ml}$ of fluid was immediately frozen for dosage of TNF activity.

Depending on the next step, loops were either filled with $5 \mathrm{ml}$ of a gentamicin solution ( $50 \mu \mathrm{g} / \mathrm{ml}$ in 0.1 M PBS) for counting of invasive intracellular bacteria, or opened and dissected for histopathological analysis.

In each rabbit, eight loops were ligated, four corresponding to villous intestine and four to Peyer's patches. Therefore a total of $\mathbf{4 8}$ blocks of villous intestine and 48 blocks of Peyer's patches were submitted to histopathological analysis.

Bacterial counts in tissue samples. These experiments were performed as recently described (8). As mentioned above, loops used for counting invasive bacteria were treated with a solution of gentamicin. This antibiotic, which penetrates poorly into cells, was used twice to eliminate as many extracellular bacteria as possible. First by replacing the fluid accumulated in the loop, and second by soaking the biopsy samples from these loops into gentamicin solution. Intestinal tissue samples were obtained by punching a disk of $8 \mathrm{~mm}$ diameter with a skin biopsy apparatus (Biopsy Punch; Stiefel, Nanterre, France). Extensive washing was performed with 0.1 M PBS to eliminate residual gentamicin, and ice-cold PBS was added to prevent further bacterial growth. Tissue samples were then ground in an Ultra-turrax apparatus (Janke \& Kunkel GmbH, Staufen, Germany) in ice-cold PBS. A 1/10 solution was obtained in TSB and incubated for $30 \mathrm{~min}$ at $37^{\circ} \mathrm{C}$. Serial dilutions of these suspensions were then plated onto Tryptic Soy agar plates. CFUs were counted and the number of bacteria was calculated for an area of $1 \mathrm{~cm}^{2}$ of intestinal mucosa.

Tissue sampling for histopathological analysis, observation, and recording of the results. All tissue samples were immediately fixed in 10\% paraformalin, dehydrated, and embedded in historesin (Leica Instruments, Heidelberg, Germany). Sequential sections were taken at different levels of the sample. Thin cuts of 1-2 $\mu \mathrm{m}$ were made and stained with hematoxylin and eosin. Histopathological observations

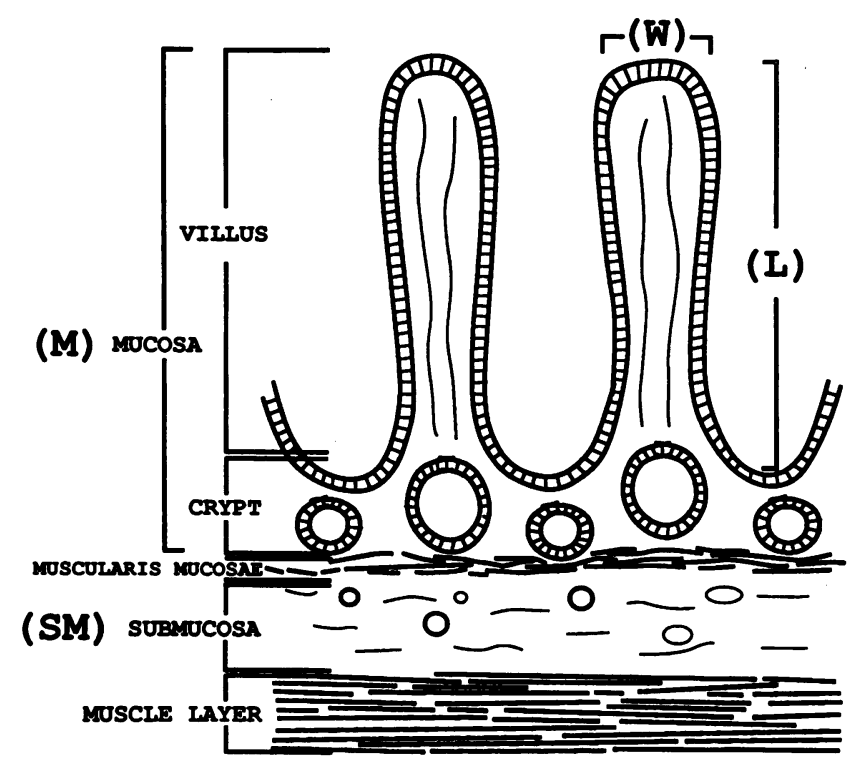

Figure 1. Schematic representation of a histopathological section of rabbit intestinal tissue. The criteria used to establish parameters of mucosal damage are shown.

were carried out as follows. For each sample, either from villous intestine or from Peyer's patches, four thin sections were observed, belonging to different areas of the block. The parameters selected to establish the criteria of villous tissue modification are shown on Fig. 1.

Four criteria were considered: $(a)$ length/width ratio $(\mathrm{L} / \mathrm{W})$ of the villi: 40 villi were measured on each thin section, their length and width were recorded, and the ratio calculated; since four thin sections were observed on each block, the mean value was therefore computed on a total of $160 \mathrm{villi} ;(b)$ percentage of villi with an ulceration; $(c)$ ratio between thickness of the submucosa and thickness of the submucosa + mucosa $(\mathrm{SM} / \mathrm{SM}+\mathrm{M})$ of villi, this ratio was calculated, based on measures taken in 10 different areas of each thin section observed. The mean was therefore calculated on $\mathbf{4 0}$ ratios for each block; $(d)$ number of PMN leukocytes invading tissues. On each of the 40 intestinal villi examined on thin sections, PMN were counted at two levels as shown on Fig. 1: in the crypt area and in the villus area. Again, the mean was calculated from a total of 160 observations for each block.

For Peyer's patches, only typical histopathological description is given.

IL-1ra bioassay. Serum levels of perfused human IL-1ra were measured at 2 and $8 \mathrm{~h}$ after initiation of the perfusion, using the Quantikine IL-1ra Immunoassay kit (Research \& Diagnostics Systems, Minneapolis, MN). Similar measures were performed in control animals. In brief, the assay used a quantitative sandwich ELISA in which a monoclonal antibody specific for human IL-1ra was coated onto a microtiter plate. After addition of serum samples, enzyme-linked polyclonal antibody specific for human IL-1ra was added, followed by washing and addition of the substrate. The enzymatic reaction was then stopped and the optical density read on a spectrophotometer. A standard curve was prepared to determine the actual concentration of IL-1ra present in each sample.

TNF bioassay. Fluid aspirated from infected loops were stored frozen for subsequent TNF bioassay. WEHI 164 (clone 13) cells were seeded $\left(3 \times 10^{4}\right.$ cells/well) in 96-well plates and incubated for $24 \mathrm{~h}$ at $37^{\circ} \mathrm{C}$ in $5 \% \mathrm{CO}_{2}$. Supernatants, in six different dilutions, were added to the assay wells, RPMI-1640 was added to negative control wells, and TNF to positive control wells. Incubation was resumed for $20 \mathrm{~h}$ at $37^{\circ} \mathrm{C}$ in $5 \% \mathrm{CO}_{2} .125 \mu \mathrm{g}$ of MTT (3-(4,5-dimethyl-thiazolyl-2-yl)-2,5diphenyltetrazoliumbromide) in PBS was added to the wells and after $2 \mathrm{~h}$ of incubation at $37^{\circ} \mathrm{C}$, the test was stopped with $100 \mu \mathrm{l}$ of extraction 
buffer ( $20 \%$ SDS, $50 \%$ dimethylformamide in $\mathrm{H}_{2} \mathrm{O}, 2.5 \% \mathrm{HCl} 1 \mathrm{~N}$, $2.5 \%$ of a $80 \%$ solution of acetic acid, $\mathrm{pH} 7.4$ ). After overnight incubation at $37^{\circ} \mathrm{C}$, the absorbance was measured at $540 \mathrm{~nm}$, using an automated microELISA autoreader (Dynatech MR4000; Dynatech, Guernesey, United Kingdom). One unit of TNF $\alpha$ activity was defined as the amount required to lyse 50\% of WEHI 164 (clone 13) target cells (14).

\section{Results}

Control of the titers of serum IL-1 ra during the course of infection, with or without perfusion of the antagonist. These controls were carried out at 2 and $8 \mathrm{~h}$ of perfusion of $2 \mathrm{mg} / \mathrm{kg}$ per h of human recombinant IL-1ra. As expected, very high serum titers of $23,282 \pm 5,649 \mathrm{pg} / \mathrm{ml}$, and $27,757 \pm 1,163 \mathrm{pg} / \mathrm{ml}$ were, respectively, observed. Control animals infected with M90T and perfused with saline showed titers $\sim 1,000 \mathrm{pg} / \mathrm{ml}$, similar to those of noninfected animals. As the assay is not designed to dosing rabbit IL-1ra, no conclusion can be drawn from these latter values.

Effect of IL-1 ra treatment on intestinal inflammation caused by $S$. flexneri. Three major criteria were used to assess the decrease of intestinal inflammation caused by continuous intravenous administration of IL-1ra during mucosal invasion by shigellae.

The volume of mucopurulent and often bloody exudate that constitutes the fluid produced in infected loops, correlates well with intensity of the inflammatory process, as already demonstrated (8). As shown in Fig. $2 A$, the average volume of exudate pooled from the eight ligated loops in each rabbit was three times higher in control animals $(57.3 \pm 36.4 \mathrm{ml})$ than in animals treated with IL-1 ra $(18.0 \pm 9.5 \mathrm{ml})$.

The amount of TNF present in the mucosal exudate has also been shown to correlate with the intensity of intestinal inflammation caused by Shigella invasion (8). As shown in Fig. $2 B$, the average quantity of TNF present in the pooled fluid of the eight loops in each control rabbit was 176.408 $\times 10^{3} \pm 16.394 \times 10^{3} \mathrm{U}$, as compared to $45.402 \times 10^{3} \pm 4.043$ $\times 10^{3} \mathrm{U}$ in animals treated with IL-1ra, a fourfold difference.

Infiltration of the lamina propria with PMN. Upon observation of histopathological sections of intestinal tissues in control animals, we noticed that PMN were migrating into the connective tissue of the lamina propria and then on to the epithelial layer, by following two routes. One corresponded to PMN extravasating from the small vessels of the submucosa, crossing the muscularis mucosae, infiltrating the lamina propria between the crypts, transmigrating to the crypt lumen, thus causing cryptitis, and also migrating higher in the axis of the villus. Another route consisted in PMN extravasating from the blood capillaries present in the villus axis, directly invading the lamina propria of the villus, and proceeding to the basal side of the epithelial layer before transmigrating to the intestinal lumen, or destroying the basement membrane, thus causing detachment of the epithelium from the villus.

Based on this observation, PMN were counted in these two "compartments," crypt and villus axis. Results are shown in Fig. $3 A$ as the average number of PMN per one villus. Numeration of PMN in the tissue of control animals was underevaluated because, in some cases, infiltrates were so dense that the actual number could not be counted. In the lamina propria of the crypts, an average number of 14.8 $\pm 6.7 \mathrm{PMN}$ was observed in the control animals, whereas only $1.8 \pm 0.68 \mathrm{PMN}$ were ob-
$\mathbf{A}$
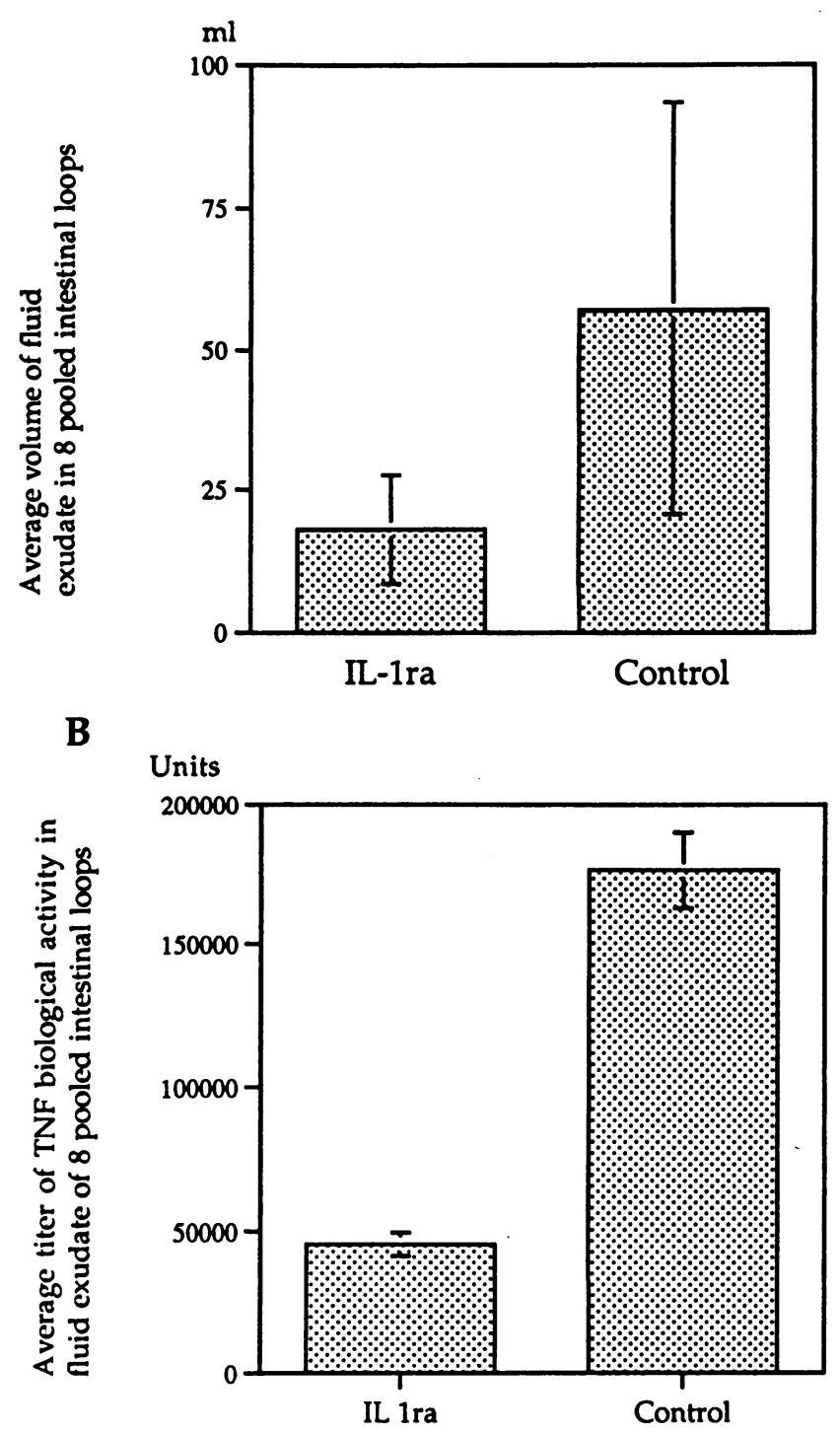

Figure 2. Characteristics of fluid exudate in infected loops of IL-1ratreated and control rabbits. Average volume $(A)$ and average TNF content $(B)$ of the pooled exudate fluid collected from the eight intestinal loops infected in each animal.

served in animals treated with IL-1ra, close to the number of PMN observed in uninfected tissues (data not shown). In the lamina propria of the villus axis, 15.2 $\pm 6.6 \mathrm{PMN}$ were counted in control animals whereas 5.7 $\pm 2.5 \mathrm{PMN}$ leukocytes were counted in animals treated with IL-1ra.

These results clearly demonstrated that perfusion of IL-1ra achieved very efficient control of the inflammatory reaction, primarily by preventing extravasation of PMN and their immigration into the lamina propria. It must be emphasized, however, that IL-1ra achieved better control of the PMN infiltrate in the crypt area than in the villus axis.

Evaluation of the degree of tissue modification and destruction. An obvious criteria of tissue alteration was the frequency of ulcerated villi. Any disruption of the continuity of the villus epithelium associated with significant inflammatory infiltrate 
$\mathbf{A}$

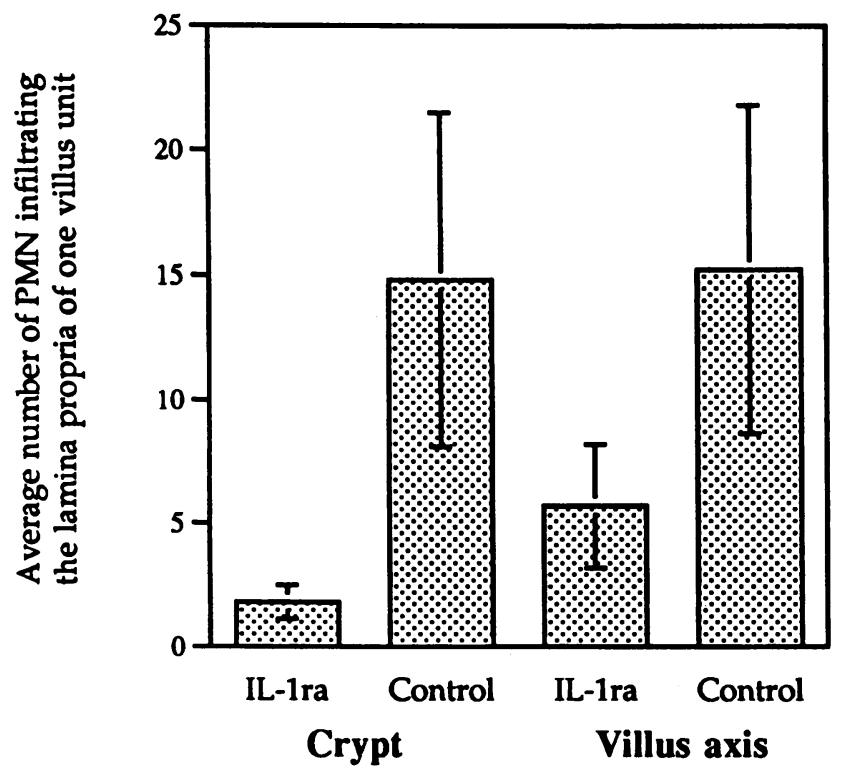

B

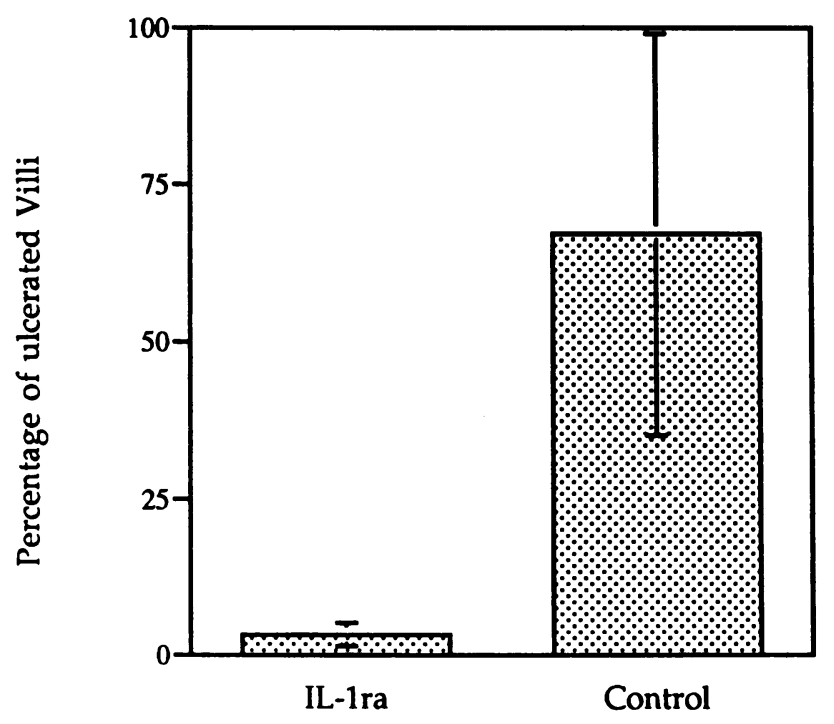

Figure 3. Tissue inflammation and destruction in IL-1ra-treated and control rabbits.. $(A)$ Average number of PMN leukocytes infiltrating the lamina propria of one crypt and one villus axis. $(B)$ Average percentage of ulcerated villi in the eight intestinal loops of each animal.

was considered as an ulceration. According to these criteria, as shown in Fig. $3 B, 67 \pm 3 \%$ of the villi presented ulcerations in control animals, whereas only $3.3 \pm 1.9 \%$ of the villi were ulcerated in animals treated with IL-1ra. Lesions ranged from limited ulcers to purulent necrosis of the entire villus. Severity of the ulcerations has not been recorded here. It must be emphasized that purulent necrosis of the entire villus was only observed in control animals, whereas animals treated with IL-1ra presented only limited ulcerations of the tip of their villi.

For more global evaluation of tissue alterations, we considered two criteria. The reduction in the length/width ratio of
A

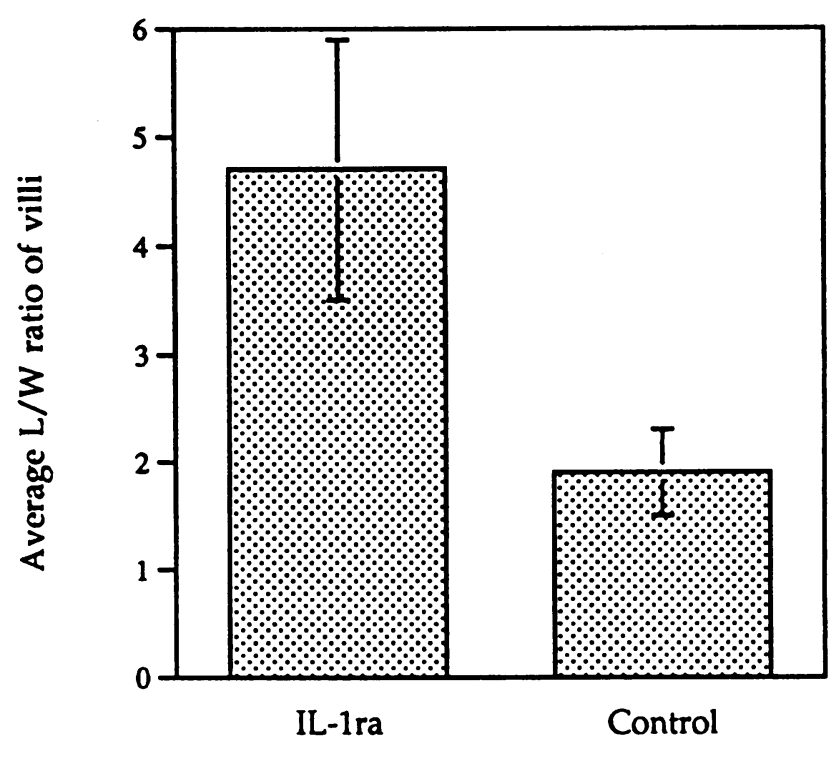

B

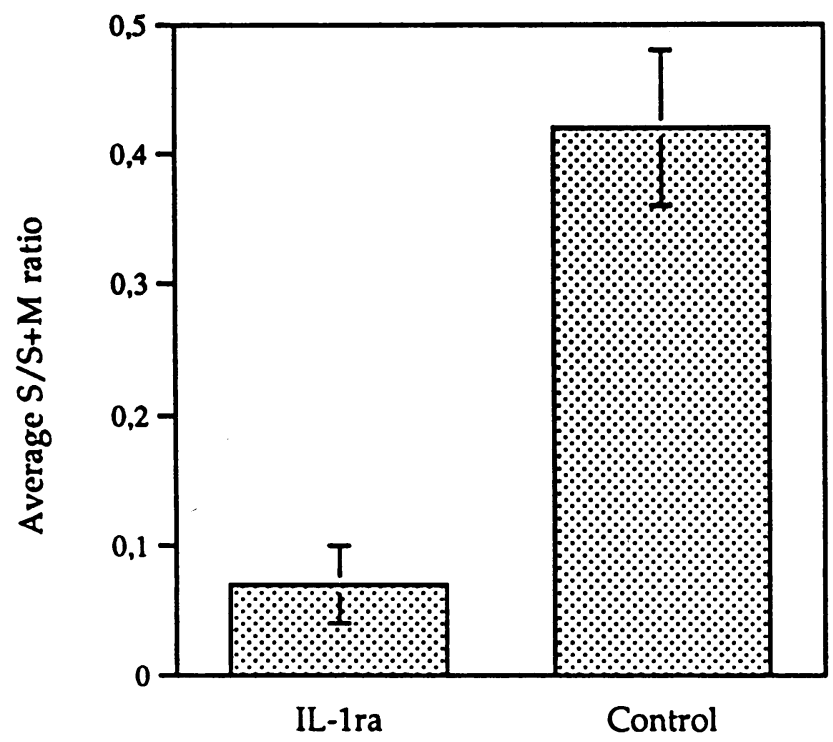

Figure 4. Villus atrophy and submucosal inflammation in IL-1 ra-treated and control rabbits. $(A)$ Average L/W ratio reflecting villus atrophy. $(B)$ Average submucosa/submucosa + mucosa ratio reflecting intensity of the submucosal edema, a characteristic of experimental shigellosis in rabbit-ligated loops.

villi, which is among the first symptoms of dysfunction in intestinal tissues (i.e., mucosal atrophy). The ratio between thickness of the submucosa and thickness of the entire mucosal plus submucosal layer, as it appeared that severe inflammation was reflected by major submucosal edema (see Fig. $5 A$ ).

Length/Width (L/W) ratio of intestinal villi is shown in Fig. $4 \mathrm{~A}$. Control animals showed striking flattening of their intestinal villi with a $\mathrm{L} / \mathrm{W}$ ratio of $1.9 \pm 0.4$ characteristic of severe villus atrophy. The actual ratio was even lower since a large number of villi were destroyed. However, only nonulcer- 

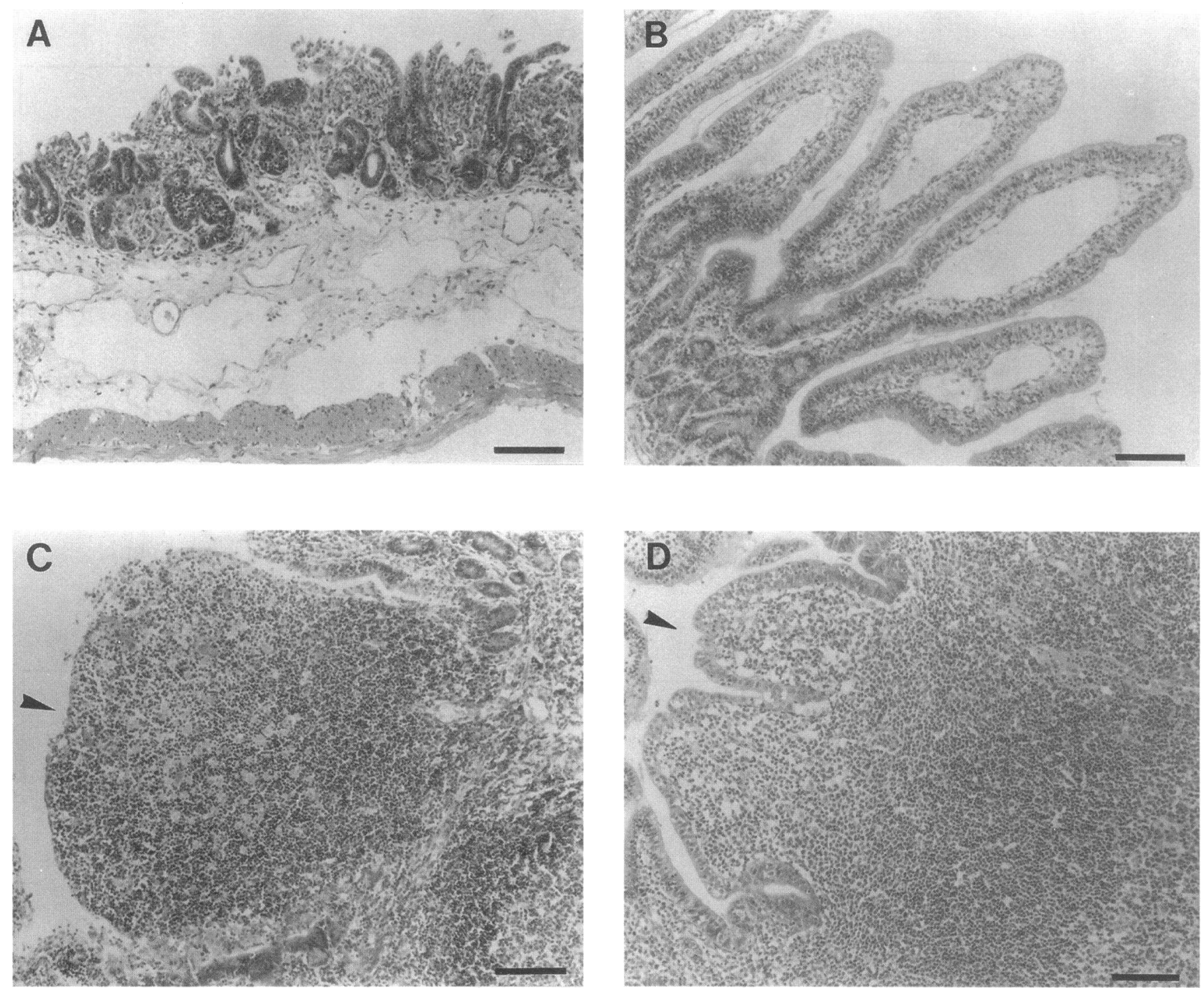

Figure 5. Characteristic aspect of villi and Peyer's patch tissue in animals infected by M90T. Bar $=30 \mu \mathrm{m}$. $(A)$ Villous intestine in control animals $(B)$ Villous intestine in animals treated by IL-1ra. $(C)$ Peyer's patch in control animals. Arrowhead points to the destroyed dome that leaves the lymphoid nodule exposed to the lumen. $(D)$ Peyer's patch in animals treated by IL-1ra. Arrowhead points to preserved epithelium of the dome in spite of a significant edema in the subepithelial zone.

ated villi or villi presenting limited tip ulcers were taken into account here. In comparison, the $\mathrm{L} / \mathrm{W}$ ratio was $4.7 \pm 1.2$ in animals treated with IL-1ra, indicating reasonable preservation of the villi structures, since the average ratio in non infected loops in this model was 6 (data not shown).

Submucosa/submucosa + mucosa ratio. These results are shown in Fig. $4 \mathrm{~B}$. Control animals showed a high ratio of 0.42 , reflecting the enormous edema that often characterized the submucosal layer of these animals. Conversely, the ratio of 0.07 observed in animals treated with IL-1ra was extremely low and equivalent to the ratio observed in noninfected loops (data not shown).

Fine histopathological analysis of the lesions. Histopathological analysis was carried out both on sections of the villous intestine and on Peyer's patches.

Examination of villous intestinal tissues revealed significant differences between samples taken from control animals and animals treated with IL-1ra. As shown in Fig. $5 \mathrm{~A}$, and already suggested in Figs. 3 and 4, the villi of control animals were either reduced in length, or destroyed by a purulent necrotic process leaving vast areas of the crypt chorion infiltrated with PMN, and dissected by large hemorrhagic foci. Complete detachment of the epithelial layer was seen in many places. The subepithelial layer was characterized by enormous edema and infiltration of inflammatory cells, primarily PMN. Numerous PMN were seen immigrating from the vessels localized in the submucosa into the lamina propria surrounding the crypts, often leading to disruption of the muscularis mucosae.

In animals treated by IL-1ra, the histopathological aspect was strikingly different. Villi were consistently altered in length and shape, but never destroyed. As shown in Fig. 5 B, they often showed a "club-like" aspect, the tip of the villus being inflated by edema, whereas the basal half of the villus and the crypt area appeared normal. As suggested in Fig. $3 A$, two compartments of PMN infiltration were constituted. One corresponding to the crypt region which is colonized by PMN immi- 
A

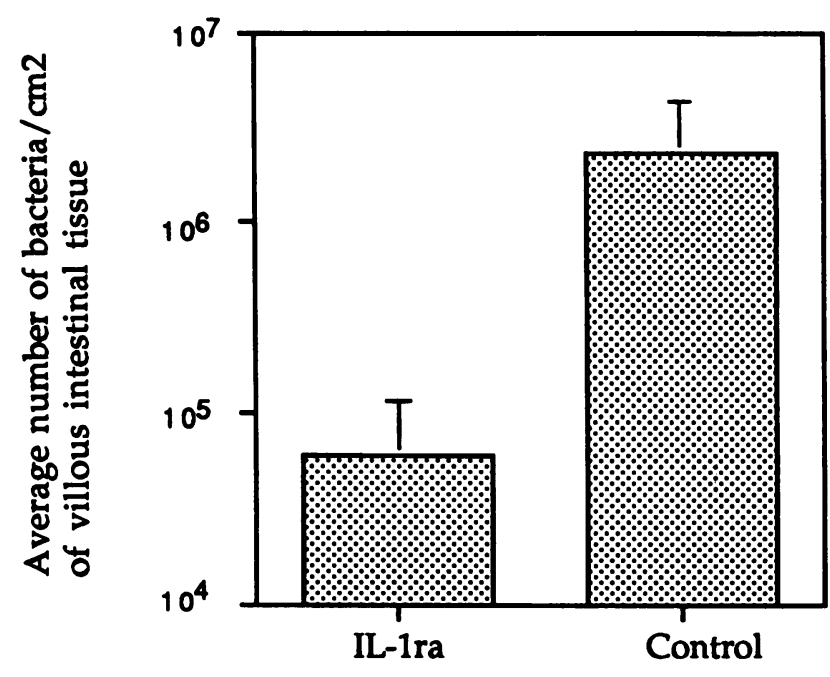

B

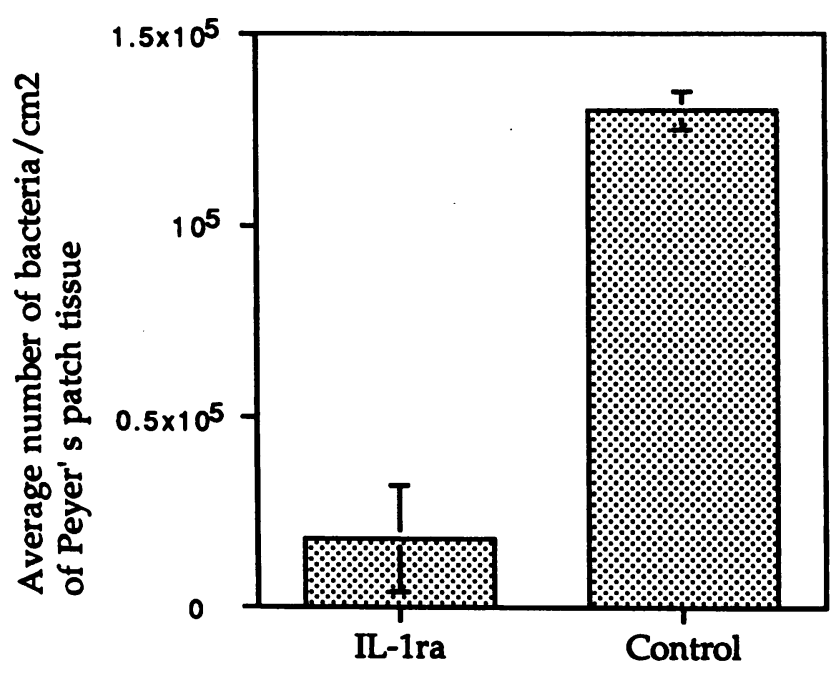

Figure 6. Tissue invasion by M90T in IL-1ra-treated and control animals. $(A)$ Average number of bacteria $/ \mathrm{cm}^{2}$ of villous intestinal tissue. (B) Average number of bacteria $/ \mathrm{cm}^{2}$ of Peyer's patch tissue.

grating from the small and medium-size vessels of the submucosa, the other corresponding to the villus axis in which PMN seem to immigrate from local capillaries. This observation suggests that IL-1ra is mainly preventing the inflammatory process elicited at the crypt level, at a distance from the bacteria, whereas it is more difficult for IL-1ra to control inflammation elicited in areas of the villus that are in close contact with the offending microorganism.

Histopathological examination of Peyer's patches also showed striking differences between control and IL-1ra-treated animals. In control animals, extensive destruction of the dome was consistently observed with intense edema and infiltration by PMN. In contrast, in IL-1ra-treated animals, in spite of significant edematous reaction and infiltration by PMN, the dome was preserved or presented only few superficial ulcers of the epithelial layer. These results are summarized in Fig. 5, $C$ and $D$.

Bacterial invasion of mucosal tissues. As shown in Fig. 6, control of the inflammatory process by IL-1ra caused significant decrease in the capacity of shigellae to invade the mucosa. The average number of bacteria per $\mathrm{cm}^{2}$ of mucosal tissue was 2.3 $\times 10^{6} \pm 2.1 \times 10^{6}$ in control animals and $6 \times 10^{4} \pm 5 \times 10^{4}$ in animals treated with the inhibitor. The average number of bacteria per $\mathrm{cm}^{2}$ of Peyer's patch tissue was $1.3 \times 10^{5} \pm 0.5 \times 10^{5}$ in control animals and $1.8 \times 10^{4} \pm 1.4 \times 10^{4}$ in animals treated with the inhibitor. Bacterial invasion of the villus mucosa was therefore reduced by a factor of $\sim 40$ in the presence of IL1ra, whereas it was reduced only by a factor of 7 in Peyer's patches tissue. This probably indicated that the physiological capacity of the epithelial dome of Peyer's patches to internalize bacteria reduced the need for an inflammatory infiltrate to destabilize the epithelial structure and facilitate invasion.

In conclusion, based on all the criteria considered, treatment of animals with IL-1 ra caused significant protection against both Shigella invasion and intestinal tissue destruction.

\section{Discussion}

There is now evidence that IL-1 is involved in the pathogenesis of inflammatory bowel diseases (IBDs). On the other hand, there has been no investigation addressing the role of this proinflammatory cytokine in the pathogenesis of an invasive infection of the gut such as shigellosis.

Clinical and histopathological observations (15), and recent experiments on the pathogenesis of shigellosis (8), suggest that a pattern of acute inflammation is initiated at the early stage of intestinal invasion by $S$. flexneri, particularly in the lymphoid follicles associated with the mucosa. In addition to ultimately causing tissue destruction, inflammation is essential to disorganizing the epithelial barrier and facilitating bacterial invasion (8). Macrophages present in the dome of lymphoid structures become infected by invasive shigellae, and some of them are rapidly killed. In vitro experiments have demonstrated that virulent $S$. flexneri causes apoptosis of infected macrophages (9). Initiation of the cell death program in macrophages preactivated with LPS induces their release of large amounts of IL- $1 \alpha$ precursor and mature IL-1 $\beta$ (11). These data suggest that releasing IL-1 may be a characteristic of resident macrophages present in the follicular dome of mucosal lymphoid structures when they phagocytose the invading pathogen. This population of macrophages, due to its permanent contact with bacterial products, particularly LPS, is probably more reactive to a pathogen like $S$. flexneri. In addition, $M$ cells themselves have the capacity to produce IL-1 after stimulation with LPS (16). Inflammation elicited in these areas may spread beyond lymphoid structures to the villous epithelium. In patients at the acute stage of shigellosis, immunohistochemical analysis of rectal biopsies, has shown a predominance of IL-1-producing cells, particularly in tissue samples showing signs of severe inflammation. Mononuclear cells, but also PMN and endothelial cells were the predominant IL-1-producing cell populations (17). These experiments therefore point to IL-1 as a likely key player in the cascade causing the inflammatory process of shigellosis.

Similarly, current evidence indicates that IL-1 plays a crucial role in colonic lesions in IBDs. This is suggested by clinical and experimental studies. Clinical studies show that IL-1 is 
transcribed and expressed at a significantly higher level by mononuclear cells purified from intestinal tissues of patients at the acute phase of IBD (16-23). In mice, recombinant IL-1 alone has been shown to be able to induce intestinal pathology, particularly villus atrophy, crypt hyperplasia, and increase in number of intraepithelial lymphocytes $(24,25)$. In the various animal models of ulcerative colitis, clear demonstration of the proinflammatory role of IL-1 has been provided by demonstrating the antiinflammatory effect of IL-1ra. Intravenous administration of this molecule before and during the development of rabbit immune complex colitis, significantly reduced all the parameters of intestinal inflammation and injury (26). These data were further confirmed in a series of experiments showing that in a similar animal model, IL-1ra did not alter the level of IL- $1 \alpha$ present in intestinal tissues, but induced a decrease in levels of proinflammatory molecules such as $\mathrm{PGE}_{2}$ and leukotriene $B_{4}(27)$. IL-1ra was also effective in reducing bowel inflammation in a model of rat colitis induced by local instillation of acetic acid (28). In addition, in various experimental models, the receptor blocking activity of IL-1ra has significantly reduced the severity of diseases such as septic shock, lethal sepsis, and experimental arthritis (29). The role of other inflammatory cytokines is less clear, although $\operatorname{TNF} \alpha, \operatorname{IFN} \gamma$, and IL- 8 are good candidates to induce further inflammation and tissue destruction. Moreover, the chronic enterocolitis and ulcerative colitis patterns observed in interleukin-2 and interleukin10 -deficient mice harboring an intestinal flora $(30,31)$ suggest that these two cytokines, particularly IL-10, a potent suppressor of macrophage activation in vitro (32), may be important negative regulators to consider in vivo in IBD as well as in shigellosis.

A major limitation to experimental approaches of shigellosis, however, is the lack of a reliable intestinal model of invasion. The guinea pig keratoconjunctivitis test is reliable to assess Shigella invasiveness but is irrelevant in this case. Mice do not develop rapid and consistent intestinal invasion by Shigella even in ligated loops. Alternatively, the rabbit-ligated loop assay appears sufficiently reliable to use it as a model of tissue invasion and inflammation. This allows us to consider using antagonists of proinflammatory molecules such as IL-1ra. This inhibitor binds to both $\mathrm{IL}-1$ receptors, but particularly relevant is its competitive binding to $\mathrm{IL}-1$ receptor 1 which blocks signal transduction induced by $\mathrm{IL}-1 \alpha$ and $\mathrm{IL}-1 \beta$. It has no agonist effect and is produced by the same cells which produce IL-1 with a delay of a few hours (33). Rabbit IL-1ra exhibits $77 \%$ amino acid sequence homology to the human molecule (34). This high degree of conservation accounts for the capacity of human recombinant IL-1ra to antagonize rabbit IL-1. These characteristics made IL-1ra the best candidate molecule to assess the role of IL-1 in shigellosis.

The present experiments have demonstrated that IL-1ra could significantly reduce the severity of intestinal lesions observed in rabbit experimental shigellosis as well as mucosal invasion by Shigella. The amount of circulating IL-1ra obtained by perfusion of $2 \mathrm{mg} / \mathrm{kg}$ per $\mathrm{h}$ in rabbits reached values of $25,000 \mathrm{pg} / \mathrm{ml}$ similar to those obtained in human volunteers by perfusion of $10 \mathrm{mg} / \mathrm{kg}$ over a period of $3 \mathrm{~h}$ (i.e., $29,000 \mathrm{pg} /$ $\mathrm{ml}$ ) (35). The general structure of the intestinal epithelium was preserved in animals treated by the inhibitor, whereas massive destruction was observed in control animals. The amount of luminal exudate was reduced, as well as its content in TNF, an established parameter of the inflammatory process of experimental, but also natural shigellosis $(8,36)$. In the complete pathogenic scheme, it is important to understand whether TNF $\alpha$ or IL-1 is the primary initiator. We are currently conducting experiments with TNF inhibitors to address this point. We would also like to evaluate how much of the epithelial destruction observed in shigellosis is due to the high titer of TNF $\alpha$ produced and secreted intraluminally. These experiments also confirm our recent observation that the severity of mucosal inflammation accounts for the extent of mucosal invasion by the bacteria $(7,8)$. It seems as if the initial interaction of the bacteria with cellular components of the intestinal barrier triggers an early inflammatory response which causes serious destabilization of epithelial cohesiveness thus facilitating further bacterial invasion.

An unexpected observation was made here concerning the traffic of extravasating PMN. IL-1ra appeared more efficient at attenuating (eliminating in many animals) immigration of PMN from submucosal vessels into the crypt lamina propria than at attenuating immigration of PMN from villi capillaries into the lamina propria occupying the upper half of intestinal villi. This caused the characteristic club-like morphology of the villi (see Fig. 5, $B$ and $E$ ), with localized edema. The reason for this "compartmentalization" of the inflammatory response remains unclear. However, it is possible that long range triggering of PMN extravasation requires a full cascade of inflammatory cytokines, IL-1 playing a major role in this process. On the other hand, elicitation of short range extravasation of PMN from villi capillaries may somewhat bypass the need for IL-1. It has recently been shown in vitro that infected epithelial cells or epithelial cells exposed to LPS are able to produce inflammatory cytokines, including the potent chemokine IL-8 $(37,38)$. Recent work indicates that Shigella dysenteriae, upon invasion of human colon epithelial cells, induces expression of IL-8, MCP1, GM-CSF, and TNF $\alpha$ (39). A similar situation in vivo may lead to direct inflammation through the epithelium by invading microorganisms. However, based on the present experiments, it appears obvious that IL-1-mediated long range inflammatory response is much more deleterious for tissues.

These observations validate the hypothesis that IL-1 plays a significant physiopathological role in shigellosis and that the macrophage, which is a major producer of IL-1 (40), is a key player in the pathogenesis of this disease, particularly in the lymphoid structures associated with the intestinal mucosa. In the current experimental system, after $8 \mathrm{~h}$ of intestinal infection in ligated loops, it is difficult to demonstrate a different reactivity of the lymphoid structures of Peyer's patches and of the villous intestine. Ligation of the intestine and high bacterial inoculum artificially facilitate invasion of the intestinal barrier. A closer model to human shigellosis is intragastric infection of macaque monkeys, followed by endoscopic observation of the colo-rectal mucosa as the disease develops ( 3 ). However, these experiments are almost impossible to achieve, particularly if constant infusion of IL-1ra needs to be maintained. The rabbit model, within well-defined limits, allows to draw conclusions on the role of IL-1 which would need definitive confirmation in a human trial as also suggested for IBD.

We believe that based on these observations, there is now solid ground to draw a parallel between shigellosis and some acute forms of IBD, particularly ulcerative colitis. In support of this idea, it is worth noting that the deleterious effect of 
IL-1 in experimental shigellosis appears rather specific of the causating pathogen Shigella. Indeed, in many other models of infection, such as Pseudomonas aeruginosa and Klebsiella pneumoniae (41), Listeria monocytogenes (42), Salmonella typhimurium (43), Escherichia coli $(44,45)$, and Mycobacterium avium (46), IL-1 was shown to play a protective role, and IL-1 blockade was reported to exacerbate the infectious process $(47,48)$. This indicates that, as in IBDs, destructive inflammation is the predominant feature of shigellosis. Whether colonic destruction is the price to pay to eradicate Shigella from tissues, or whether these bacteria, even at low inoculum, can generate massive uncontrolled inflammation, remains to be analyzed.

Finally, it is not at all clear how shigellosis resolves. It as been shown that healthy human volunteers receiving $E$. coli endotoxin showed plasma levels of $I L-1 \beta$ peaking at $79 \mathrm{pg} / \mathrm{ml}$, whereas their levels of IL-1ra, 1-3 h later were $\sim 100$-fold higher (49). This excess amount of IL-1ra may be sufficient to antagonize the biological effect of IL-1 $\beta$. Moreover, in acutely ill surgical patients, very high levels of IL-1ra (i.e., 54,300 $\mathrm{pg} / \mathrm{ml}$ ) have been observed (50). This indicates that serious conditions (with or without sepsis) may cause circulating levels of IL-1ra equivalent to those obtained by perfusion, ranging between 1 and $10 \mathrm{mg} / \mathrm{kg}$ per $\mathrm{h}$. We can therefore speculate that a physiological increase of IL-1ra to high titers may be observed in the course of severe sepsis such as shigellosis. IL-1ra titers produced locally by intestinal mononuclear cells and possibly other cell populations may account for efficient antagonism of $\mathrm{IL}-1 \beta$, thus leading to healing.

\section{Acknowledgments}

We are extremely indebted to Synergen, especially, Dr. James L. Vannice for his generous provision of recombinant IL-1ra. It is obvious that without their help, this work would not have been possible. We also wish to thank Catherine Fitting for cytokine measurement, Nicole Wuscher for her expertise in histopathological studies, and Colette Jacquemin for the editing of this manuscript.

This work was in part funded by the European Union (EEC grant No. BI02 - CT 92-0134).

\section{References}

1. LaBrec, E. H., H. Schneider, T. J. Magnani, and S. B. Formal. 1964. Epithelial cell penetration as an essential step in the pathogenesis of bacillary dysentery. J. Bacteriol. 88:1503-1518.

2. Goldberg, M. B., and P. J. Sansonetti. 1993. Shigella subversion of the cellular cytoskeleton: a strategy for epithelial colonization. Infect. Immun. 61:4941-4946.

3. Sansonetti, P. J., J. Arondel, A. Fontaine, H. d'Hauteville, and M. L. Bernardini. 1991. OmpB (osmo-regulation) and icsA (cell to cell spread) mutants of Shigella flexneri. Evaluation as vaccine candidates. Probes to study the pathogenesis of shigellosis. Vaccine. 9:416-422.

4. Mathan, M. M., and V. I. Mathan. 1986. Ultrastructural pathology of the rectal mucosa in Shigella dysentery. Am. J. Pathol. 123:25-38.

5. DuPont, H. L., M. M. Levine, R. B. Hornick, and S. B. Formal. 1989. Inoculum size in shigellosis and implications for expected mode of transmission. J. Infect. Dis. 159:1226-1228.

6. Mounier J. T. Vasselon, R. Hellio, M. Lesourd, and P. J. Sansonetti. 1992. Shigella flexneri enters human colonic Caco-2 epithelial cells through their basolateral pole. Infect. Immun. 60:237-248.

7. Perdomo, J. J., P. Gounon, and P. J. Sansonetti. 1994. Polymorphonuclear leukocyte (PMN) transmigration promotes invasion of colonic epithelial monolayer by Shigella flexneri. J. Clin. Invest. 93:633-643.

8. Perdomo, J. J., J. M. Cavaillon, M. Huerre, H. Ohayon, P. Gounon, and P. J. Sansonetti. 1994. Acute inflammation causes epithelial invasion and mucosal destruction in experimental shigellosis. J. Exp. Med. 180:1307-1319.
9. Zychlinsky, A., M. C. Prévost, and P. J. Sansonetti. 1992. Shigella flexneri induces apoptosis in infected macrophages. Nature (Lond.). 358:167-168.

10. Zychlinsky, A., B. Kenny, R. Ménard, M. C. Prévost, I. B. Holland, and P. J. Sansonetti. 1994. IpaB mediates macrophage apoptosis induced by Shigella flexneri. Mol. Microbiol. 11:619-627.

11. Zychlinsky, A., C. Fitting, J. M. Cavaillon, and P. J. Sansonetti. 1994. Interleukin-1 is released by macrophages during apoptosis induced by Shigella flexneri. J. Clin. Invest. 94:1328-1332.

12. Wassef, J., D. F. Keren, and J. L. Mailloux. 1989. Role of $M$ cells in initial bacterial uptake and in ulcer formation in the rabbit intestinal loop model in shigellosis. Infect. Immun. 57:858-863.

13. Sansonetti, P. J., D. J. Kopecko, and S. B. Formal. 1982. Involvement of a plasmid in the invasive ability of Shigella flexneri. Infect. Immun. 35:852-860.

14. Cavaillon, J. M., C. Fitting, N. Haennfner-Cavaillon, S. T. Kirsch, and H. S. Warren. 1990. Cytokine response by monocytes and macrophages to free and lipoprotein bound lipopolysaccharide. Infect. Immun. 58:2375-2382.

15. Mathan, M. M., and V. I. Mathan. 1991. Morphology of rectal mucosa of patients with shigellosis. Rev. Infect. Dis. 13 (Suppl. 4):S314-S318.

16. Pappo, J., and R. T. Mahlman. 1993. Follicle epithelial $M$ cells are a source of interleukin-1 in Peyer's patches. Immunology. 78:505-507.

17. Raquib, R., A. A. Lindberg, B. Wretlind, P. K. Bardhan, U. Andersson, and J. Andersson. 1995. Persistence of local cytokine production in shigellosis in acute and convalescent stages. Infect. Immun. 63:289-296.

18. Sartor, R. B. 1991. Pathogenic and clinical relevance of cytokines in inflammatory bowel disease. Immunol. Res. 10:465-471.

19. Mahida, Y. R., K. Wu, and D. P. Jewell. 1989. Enhanced production of interleukin $1-\beta$ by mononuclear cells isolated from mucosa with active ulcerative colitis or Crohn's disease. Gut. 30:835-838.

20. Isaacs, K. L., R. B. Sartor, and S. Haskill. 1992. Cytokine messenger RNA profiles in inflammatory bowel disease mucosa detected by polymerase chain reaction amplification. Gastroenterology. 103:1587-1595.

21. Youngman, K. R., P. L. Simon, G. A. West, F. Cominelli, D. Rachmilewitz, J. S. Klein, and C. Fiocchi. 1993. Localization of intestinal interleukin-1 activity and protein and gene expression to lamina propria cells. Gastroenterology. 104:749-758.

22. Ligumsky, M., P. L. Simon, F. Karmeli, D. Rachmilewitz. 1990. Role of interleukin-1 in inflammatory bowel disease-enhanced production during active disease. Gut. 31:686-689.

23. Satsangi, J., R. A. Wolstencroft, J. Cason, C. C. Ainley, D. C. Dumona and R. P. Thompson. 1989. Interleukin-1 in Crohn's disease. Clin. Exp. Immunol. 67:594-604.

24. Mowat, A. M., A. K. Hutton, P. Garside, and M. Steel. 1993. A role for Interleukin- $1 \alpha$ in immunologically mediated intestinal pathology. Immunology. 80:110-115.

25. Brynskov, J., N. Tvede, C. B. Andersen, and M. Vilien. 1992. Increased concentrations of interleukin- $1 \beta$, interleukin- 2 , and soluble interleukin- 2 receptors in endoscopical mucosal biopsy specimens with active inflammatory bowel disease. Gut. 33:55-58.

26. Cominelli, F., C. C. Nast, B. D. Clark, R. Schindler, R. Llerena, V. E Eysselein, R. C. Thompson, and C. A. Dinarello. 1990. Interleukin 1 (IL-1) gene expression, synthesis, and effect of specific IL-1 receptor blockade in rabbit immune complex colitis. J. Clin. Invest. 86:972-980.

27. Cominelli, F., C. C. Nast, A. Duchini, and M. Lee. 1992. Recombinant Interleukin-1 receptor antagonist blocks the pro-inflammatory activity of endogenous Interleukin-1 in rabbit immune colitis. Gastroenterology. 103:65-71.

28. Thomas, T. K., P. C. Will, A. Srivastava, C. L. Wilson, M. Harbison, J. Little, R. S. Chesonis, M. Pignatello, D. Schmolze, J. Symington, et al. 1991 Evaluation of an interleukin-1 receptor antagonist in the rat acetic acid-induced colitis model. Agents Actions. 34:187-192.

29. Dinarello, C. A. 1992. The role of interleukin-1 in host responses to infectious diseases. Infect. Agents Dis. 1:227-236.

30. Sadlack, B., H. Merz, H. Schorle, A. Schimpl, A. C. Feller, and I. Horak 1993. Ulcerative colitis-like disease in mice with a disrupted interleukin-2 gene. Cell. 75:253-261.

31. Kühn, R., J. Löhler, D. Rennick, K. Rajewsky, and W. Müller. 1993. Interleukin-10-deficient mice develop chronic enterocolitis. Cell. 75:263-274.

32. Fiorentino, D. F., A. Zlotnik, T. R. Mosmann, M. Howard, and A. O'Garra 1991. IL-10 inhibits cytokine production by activated macrophages. J. Immunol. 147:3815-3822.

33. Arend, W. P. 1993. Interleukin-1 receptor antagonist. Adv. Immunol. 54:167-227.

34. Goto, F., K. Goto, T. Miyata, S. Ohkawara, T. Takao, T. Mori, S. Furukawa, T. Maeda, S. Iwanaga, Y. Shimouishi, and M. Yoshinaga. 1992. Interleukin1 receptor antagonist in inflammatory exudate cells of rabbits. Production, purification and determination of primary structure. Immunology. 77:235-244.

35. Granowitz, E. V., R. Porat, J. V. Mier, J. P. Pribble, D. M. Stiles, D. C. Bloedow, M. A. Catalano, S. M. Wolff, and C. A. Dinarello. 1992. Pharmacokinet- 
ics, safety and immunomodulatory effects of human recombinant interleukin-1 receptor antagonist in healthy humans. Cytokine. 4:353-360.

36. Nicholls, S., S. Stephens, C. P. Braegger, J. A. Walker-Smith, and T. T. MacDonald. 1993. Cytokines in stools of children with inflammatory bowel disease or infective diarrhoea. J. Clin. Pathol. 46:757-760.

37. Eckmann, L., M. F. Kagnoff, and J. Fierer. 1993. Epithelial cells secrete the chemokine Interleukin-8 in response to bacterial entry. Infect. Immun. 61:4569-4574.

38. Schueker-Maly, C. C., L. Eckmann, M. F. Kagnoff, M. T. Falco, and F. E. Maly. 1994. Colonic epithelial cell lines as a source of interleukin-8: stimulation by inflammatory cytokines and bacterial lipopolysaccharide. Immunology. 81:85-91.

39. Jung, H. C., L. Eckmann, S.-K. Yang, P. Asit, J. Fierer, E. MorzyckaWroblewska, and M. Kagnoff. 1995. A distinct array of proinflammatory cytokines is expressed in human colon epithelial cells in response to bacterial invasion. $J$. Clin. Invest. 95:55-65.

40. Dinarello, C. A. 1991. Interleukin-1 and interleukin-1 antagonism. Blood. $77: 1627-1652$

41. Ozaki, Y., T. Ohashi, A. Minami, and S. I. Nakamura. 1987. Enhanced resistance of mice to bacterial infection induced by recombinant interleukin- $1 \alpha$. Infect. Immun. 55:1436-1440.

42. Czuprynski, C. J., and J. F. Brown. 1987. Recombinant murine interleukinla enhancement of non-specific antibacterial resistance. Infect. Immun. 55:20612065.
43. Morrissey, P., and J. Charrier. 1991. Interleukin-1 administration to C3H/ HeJ mice after but not prior to infection increases resistance to Salmonella typhimurium. Infect. Immun. 59:4729-4731.

44. Pelkonen, S., and G. Pluschke. 1989. Recombinant interleukin-1 stimulates clearance of Escherichia coli K1 bacteraemia. Microb. Pathog. 6:415-424.

45. Cross, A. S., J. C. Sadoff, N. Kelly, E. Bernton, and P. Gemski. 1989. Pretreatment with recombinant murine tumor necrosis factor- $\alpha$ and murine interleukin-1 $\alpha$ protect mice from lethal bacterial infection. J. Exp. Med. 169:20212027.

46. Denis, M., and E. Gharirian. 1994. Interleukin-1 is involved in mouse resistance to Mycobacterium avium. Infect. Immun. 62:457-461.

47. Mancilla, J., P. Garcia, and C. A. Dinarello. 1993. The interleukin-1 receptor antagonist can either reduce or enhance the lethality of Klebsiella pneumoniae sepsis in newborn rats. Infect. Immun. 61:926-932.

48. Havell, E. A. L. L. Moldawer, D. Helfgott, P. L. Kilian, and P. B. Sehgal. 1992. Type I IL-1 receptor blockade exacerbates murine listeriosis. J. Immunol. 148:1486-1492.

49. Granowitz, E. V., A. A. Santos, D. D. Poutsiaka, J. G. Cannon, D. W. Wilmore, S. M. Wolff, and C. A. Dinarello. 1991. Production of interleukin-1receptor antagonist during experimental endotoxaemia. Lancet. 338:1423-1424.

50. Fischer, E., K. J. Van Zee, M. A. Marano, C. S. Rock, J. S. Kenney, D. D. Pontsiaka, C. A. Dinarello, S. F. Lowry, and L. L. Moldawer. 1992. Interleukin-1 receptor antagonist circulates in experimental inflammation and in human disease. Blood. 79:2196-2200. 